\title{
On the use of methane as a carbon precursor in Chemical Vapor Deposition of silicon carbide
}

Milan Yazdanfar, Henrik Pedersen, Pitsiri Sukkaew, Ivan Gueorguiev Ivanov, O. Danielsson, Olle Kordina and Erik Janzén

\section{Linköping University Post Print}

\section{Tweet}

N.B.: When citing this work, cite the original article.

Original Publication:

Milan Yazdanfar, Henrik Pedersen, Pitsiri Sukkaew, Ivan Gueorguiev Ivanov, O. Danielsson, Olle Kordina and Erik Janzén, On the use of methane as a carbon precursor in Chemical Vapor Deposition of silicon carbide, 2014, Journal of Crystal Growth, (390), 24-29.

http://dx.doi.org/10.1016/j.jcrysgro.2013.12.033

Copyright: Elsevier http://www.elsevier.com/

Postprint available at: Linköping University Electronic Press http://urn.kb.se/resolve?urn=urn:nbn:se:liu:diva-107126 


\section{On the use of Methane as Carbon Precursor in Chemical Vapor Deposition of Silicon Carbide}

M. Yazdanfar*, H. Pedersen, P. Sukkaew, I. G. Ivanov, Ö. Danielsson, O.Kordina, E. Janzén

Department of Physics, Chemistry and Biology, Linköping University, SE-581 83 Linköping, SWEDEN

*Corresponding author: e-mail: milya@ifm.liu.se, tel: +46 13 282659, fax: +46 13137568 


\section{Abstract:}

It is generally considered that methane is not a suitable carbon precursor for growth of silicon carbide ( $\mathrm{SiC}$ ) epitaxial layers by chemical vapor deposition (CVD) since its use renders epitaxial layers with very high surface roughness. In this work we demonstrate that in fact $\mathrm{SiC}$ epitaxial layers with high-quality morphology can be grown using methane. It is shown that a key factor in obtaining high-quality material is tuning the $\mathrm{C} / \mathrm{Si}$ ratio of the process gas mixture to a region where the growth is limited neither by carbon nor by silicon supplies. From the growth characteristics presented here, we argue that the reactivity of methane with the $\mathrm{SiC}$ surface is much higher than generally assumed in $\mathrm{SiC}$ CVD modeling today.

\section{Keywords:}

A3. CVD, A3. Chloride-based, B. SiC, B. Silicon Carbide, B. Methane 


\section{Introduction}

Silicon carbide $(\mathrm{SiC})$ is not only a very hard material but also a promising material for high power and high frequency electronic devices due to its high breakdown electric field, high thermal conductivity and high saturation electron drift velocity [1, 2]. Chemical Vapor Deposition (CVD) is the most common route of growing epitaxial layers of Silicon Carbide (SiC) for electronic applications. Commonly, silane $\left(\mathrm{SiH}_{4}\right)$ and light hydrocarbons e.g. propane $\left(\mathrm{C}_{3} \mathrm{H}_{8}\right)$ or ethylene $\left(\mathrm{C}_{2} \mathrm{H}_{4}\right)$ are used as silicon and carbon precursors, respectively. The precursors are typically diluted in a carrier gas flow of hydrogen $\left(\mathrm{H}_{2}\right)$, or a mixture of hydrogen and argon, and transported into the reactor where SiC growth takes place at typically $1500-1600{ }^{\circ} \mathrm{C}$. It is generally considered that the most simple hydrocarbon molecule, methane $\left(\mathrm{CH}_{4}\right)$, is not a suitable carbon precursor for growth of SiC epitaxial layers since a CVD process with methane commonly renders epitaxial layers with high surface roughness and high density of surface defects [3]. The bad morphology is ascribed to the lower reactivity, i.e. higher thermal decomposition temperature, of methane compared to, e.g., propane; this lower reactivity can be attributed to the very high symmetry of the molecule (point group $T_{d}$ in the Schoenflies notation).

The introduction of chloride-based growth chemistry in SiC CVD has enabled considerably higher growth rates of epitaxial SiC layers [4] owing to the different gas phase [5] and surface chemistry [6] initiated by the presence of chlorine, and has also made a high temperature chlorinated $\mathrm{SiC}$ bulk growth process possible [7]. In the process proposed by Fanton et al [7]., where high temperatures of around $2000^{\circ} \mathrm{C}$ are used, methane has proven to be the best carbon precursor yielding a more stable process with less formation of solid carbon in the gas inlet.

If methane could be used as SiC CVD precursor, major improvements to the SiC CVD process would be possible. Methane can effortlessly be obtained in higher purities than 
most other hydrocarbons which would reflect on the impurity incorporation of the grown $\mathrm{SiC}$ layers. Also, methane is the only hydrocarbon that reasonably easy can be obtained in an isotopically enriched form with the ${ }^{12} \mathrm{C}$ isotope. When using isotopically enriched precursors in the SiC CVD process, enriched ${ }^{28} \mathrm{Si}^{12} \mathrm{C}$ can be grown which augments the material properties, for instance, the thermal conductivity is expected to increase markedly [8]. Since methane is the only enriched hydrocarbon available at present, the ability to use methane in SiC CVD becomes vital in order to realize ${ }^{28} \mathrm{Si}^{12} \mathrm{C}$ material. This motivates the present study in which we describe the characteristics of SiC CVD using methane as carbon precursor in a chloride-based CVD process and compare them with those of the more common ethylene-based epitaxy.

\section{Experimental details}

CVD of SiC was done in a hot wall reactor without substrate rotation, conceptually described in detail earlier [9], using silane $\left(\mathrm{SiH}_{4}\right)$ as silicon precursor and either methane $\left(\mathrm{CH}_{4}\right)$ or ethylene $\left(\mathrm{C}_{2} \mathrm{H}_{4}\right)$ as carbon precursor. The precursors were diluted approximately 400 times in a palladium membrane purified hydrogen gas flow of $50 \mathrm{l} / \mathrm{min}$. The chloride based growth chemistry was achieved through the addition of $\mathrm{HCl}$, with a $\mathrm{Cl} / \mathrm{Si}$ ratio of 4 , to the gas mixture. No intentional dopants were added to the gas mixture. Growth experiments were done at a temperature of $1575^{\circ} \mathrm{C}$ and a pressure of 100 mbar. Epitaxial growth was done on $4 \mathrm{H}-\mathrm{SiC}$ with $4^{\circ}$ off-cut from the c-axis; $15 \times 15 \mathrm{~mm}^{2}$ pieces, cut from one wafer, were used as substrates. The growth experiments used the in-situ surface preparation previously described for $4^{\circ}$ off axis $4 \mathrm{H}-\mathrm{SiC}$ substrates [10], and a growth time of 15 minutes.

The thickness of the grown epitaxial layers was measured by FT-IR reflectance and the morphology of the epitaxial layers was studied using optical microscope with Nomarski differential interference contrast and in greater detail using atomic force microscopy (AFM) 
in tapping mode on a $20 \times 20 \mu \mathrm{m}^{2}$ surface at the center of the substrate and at two different areas close to the periphery, about $2 \mathrm{~mm}$ from the edge. The surface roughness of the samples was quantified by the root mean square (RMS) value of the height variations over the scanned area by AFM. The net carrier concentration of the epitaxial layers was determined from capacitance-voltage (CV) measurements using a mercuryprobe. Low temperature photoluminescence (LTPL) at $2 \mathrm{~K}$ using as an excitation $244 \mathrm{~nm}$ from a frequency doubled Argon ion laser was employed to study the quality of the grown epitaxial layers.

\section{Results and Discussion}

The obtained growth rates are plotted in Fig. 1 for various $\mathrm{C} / \mathrm{Si}$ ratios in the input gas mixture while maintaining constant silane flow $(125 \mathrm{ml} / \mathrm{min})$. In the silicon limited growth region, where the growth is controlled by the silicon supply, the growth rate becomes constant for higher flows of the carbon precursor. It is interesting to note that this constant level is somewhat lower when using methane compared to when using ethylene. Theoretically, the growth rate in this region should only depend on the supply of $\mathrm{Si}$ atoms, not by the nature of the hydrocarbon, suggesting that there are unknown aspects of the growth chemistry that have to be considered. One such possible aspect is the not yet fully understood role of the organosilicon molecules, i.e. molecules of the formula $\mathrm{Si}_{x} \mathrm{C}_{y} \mathrm{H}_{z}$ where $x, y$ and $z$ are all $\geq 1$, in the growth process. It is reasonable to anticipate that the chemical routes for formation of organosilicons will be different for methane and for hydrocarbon molecules with one or more C-C bonds, which have different pyrolysis chemistry $[11,12]$. The route for formation of organosilicons from methane might be less efficient leading to a lower amount of organosilicons available for SiC growth when methane is used as carbon precursor. The role of the organosilicons in SiC CVD is not yet completely clarified. On the one hand, based on experimental studies it has been 
suggested that organosilicons are not the major contributors to the growth [13]. On the other hand, simulation studies have suggested that contributions from $\mathrm{Si}_{2} \mathrm{C}$ and $\mathrm{SiCH}_{2}$ are important for SiC growth [14]. However at the chosen growth conditions, position of the substrate, and the possibly different routes of the organosilicon chemistry cannot alone explain differences of this magnitude, so this explanation cannot stand on its own. Another possible explanation for the lower saturation value of the growth rate when using methane might be that the upstream depletion of $\mathrm{Si}$ is larger in this case. This may hold true if the adsorption rate of $\mathrm{Si}$ on $\mathrm{Si}($ or $\mathrm{Si}-\mathrm{H}$ ) terminated surfaces is larger than that of $\mathrm{Si}$ on $\mathrm{C}$ (or $\mathrm{C}$ $\mathrm{H})$ terminated surfaces at the lower temperatures present in the entrance zone of the reaction chamber, which would deplete the silicon supply upstream. It is natural to consider such scenario because methane is more stable than ethylene and thus decompose further downstream into the reaction chamber making any upstream deposition more rich in silicon, compared to the ethylene based process. A third possible explanation for the observed behavior is that the reactivity of methane with a $\mathrm{Si}$ or $\mathrm{Si}-\mathrm{H}$ terminated surface is in fact quite substantial as opposed to the very low sticking probability of $5.0 \times 10^{-5}$ commonly considered in the literature [15]. It should be noted that this value was estimated from experiments where methane was adsorbed on silicon surfaces at $1495 \mathrm{~K}$ [16], i.e. substantially lower temperature than commonly used for CVD of SiC. The authors describe that the Si surface was immediately covered by C-atoms and new Si was supplied via diffusion through grain boundaries of the formed $\mathrm{SiC}$ and that their measurements thus could be used for the understanding of SiC CVD [16]. These adsorption experiments were done without any hydrogen present which adds to the skepticism towards the low value of the sticking probability, since computational studies have shown that the $\mathrm{SiC}$ surface is likely to be hydrogen terminated at typical SiC CVD conditions $[17,18]$. If we adopt the idea that methane has actually higher sticking probability, it is natural to anticipate significant upstream depletion of both Si and C leading 
to a lower growth rate at the substrate position in the susceptor. At a first glance it might not be obvious that a higher adsorption rate of methane leads to a higher depletion of $\mathrm{Si}$, but since Si would preferably adsorb on a C-terminated (or $\mathrm{C}-\mathrm{H}$ terminated) surface then the natural consequence of a surface that is $\mathrm{C}-\mathrm{H}$ terminated to a major extent is that Si will deplete due to the higher abundance of suitable "sticking" sites.

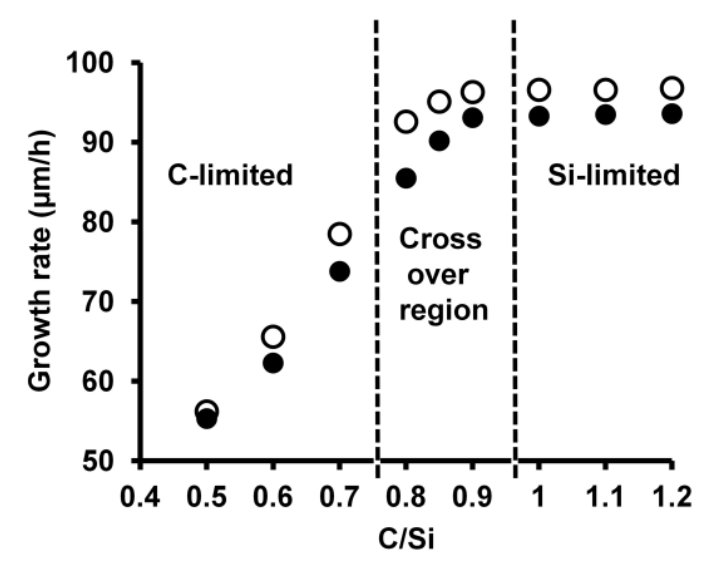

Fig. 1. Growth rates for different $\mathrm{C} / \mathrm{Si}$ ratios (keeping silane and $\mathrm{HCl}$ flows constant) in the gas mixture using either methane (closed circles) or ethylene (open circles) as carbon precursor. The carbon limited (Climited) and silicon limited (Si-limited) growth regions are indicated in the figure as well as the cross over region where growth is limited neither by carbon, nor by silicon.

Another observation from Fig. 1 is that in the cross over region between the C-limited and the Si-limited growth regions, the knee point when the growth switches from carbon limited (growth rate increases with increasing $\mathrm{C} / \mathrm{Si}$ ratio) to silicon limited growth mode (growth rate levels up), appears to be at a somewhat higher $\mathrm{C} / \mathrm{Si}$ ratio for growth using methane than for growth using ethylene. This contradicts with the second speculation mentioned above, i.e., that $\mathrm{Si}$ should deplete more in the upstream region when using methane as carbon precursor. If this argument would be true, the knee point would come at a lower $\mathrm{C} / \mathrm{Si}$ ratio for growth using methane since the actual $\mathrm{C} / \mathrm{Si}$ in the growth zone would be 
higher due to the loss of silicon. Also, if $\mathrm{Si}$ would deposit on $\mathrm{Si}$ (or $\mathrm{Si}-\mathrm{H})$ this process would be the same regardless of which hydrocarbon is used. The shape of the two curves in the cross over region is also interesting to consider; the knee point appears more distinct for the CVD process using methane than for that with ethylene. This is a further indication that the growth chemistries for the two hydrocarbons are different. Ethylene is commonly considered to decompose predominantly to acetylene $\left(\mathrm{C}_{2} \mathrm{H}_{2}\right)$ in the gas phase [5]. If we assume that the low reactivity of methane in the gas-phase leads to decomposition of only a fraction of the molecules to $\mathrm{CH}_{3}$, then the dominant species responsible for growth in the methane and ethylene case will be methane and acetylene, respectively. In order to make use of both $\mathrm{C}$-atoms in the acetylene molecule, the molecule needs to attach to two adjacent silicon or hydrogen terminated silicon ( $\mathrm{Si}-\mathrm{H})$ sites. In the cross over region, it may be less likely to find adjacent sites such as these in which case only one of the carbon atoms can bond to the surface and the other carbon will break off and most likely not contribute to the SiC growth. This would make the knee point less precise for the ethylene case. In the case of methane, on the other hand, only one free Si or Si-H site is required which would lead to a much more distinct knee point, similar to what is observed in Fig. 1.

It can further be noted from Fig. 1 that the difference in growth rate when using methane or ethylene is reduced when using very low $\mathrm{C} / \mathrm{Si}$ ratios $(\mathrm{C} / \mathrm{Si}=0.5$ in Fig. 1), i.e. for highly carbon limited growth. This can be attributed to the diminishing role of the differences in the growth chemistries generated by the two hydrocarbons with the reduction of the carbon supply. The trend that ethylene yields higher growth rate than methane is confirmed for growth rates between 75 and $110 \mu \mathrm{m} / \mathrm{h}$ at $\mathrm{C} / \mathrm{Si}=1$, the growth rate was here varied by changing the concentration of precursors in the gas mixture, keeping $\mathrm{C} / \mathrm{Si}=1$.

Another indication that ethylene is a superior precursor to methane is that the background doping level is somewhat lower for unintentionally doped epitaxial layers grown using 
ethylene compared to layers grown with methane: The background net carrier concentration $\left(\mathrm{N}_{\mathrm{d}}-\mathrm{N}_{\mathrm{a}}\right)$ for growth with $\mathrm{C} / \mathrm{Si}=1.2,0.9$ and 0.5 were $9 \times 10^{13}, 5.5 \times 10^{14}$, and $4.6 \times 10^{15} \mathrm{~cm}^{-3}$, respectively, when using methane, and $7.5 \times 10^{13}, 4.0 \times 10^{14}$, and $3.0 \times 10^{15}$ $\mathrm{cm}^{-3}$, respectively, using ethylene. The higher $n$-type doping, caused by incorporation of nitrogen in the $\mathrm{SiC}$ lattice, indicates that the $\mathrm{C} / \mathrm{Si}$ ratio is somewhat lower on the $\mathrm{SiC}$ surface when using methane [19], allowing more nitrogen to incorporate in the SiC lattice. It should be noted that the nitrogen incorporation has previously been shown to be independent of growth rate in chloride-based CVD of SiC [20], and the difference in doping between layers grown with methane and ethylene is most likely due to different effective $\mathrm{C} / \mathrm{Si}$ ratio on the surface when the two different precursors are used. The doping levels in the epitaxial layers thus suggest that the carbon supply to the surface is less efficient in the case of methane.

The surface morphology of the epitaxial layers is quantified by the surface roughness measured by means of atomic force microscopy (AFM) and the results are presented in Fig. 2. The surface roughness varies significantly with the $\mathrm{C} / \mathrm{Si}$ ratio and is optimal in the cross-over region for both $\mathrm{C}$ precursors. We notice also that the overall surface morphology is better with ethylene than with methane, however, the optimal $\mathrm{C} / \mathrm{Si}$ ratio (within the cross-over region) produces very similar surface roughness for both precursors. The significant differences away from the optimal $\mathrm{C} / \mathrm{Si}$ ratio witnesses once again for the different growth chemistry for ethylene and methane, in favor of ethylene in both C-rich and Si-rich conditions. 


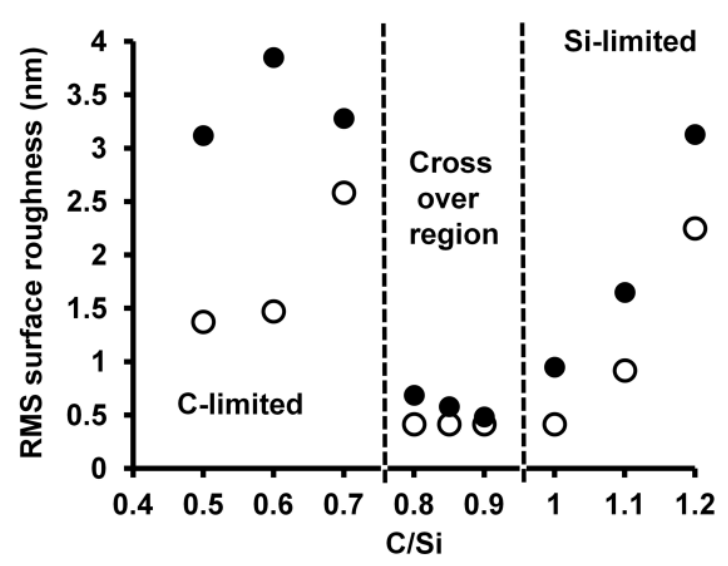

Fig. 2. Root mean square (RMS) values of the surface roughness as measured by AFM on a $20 \times 20 \mu m^{2}$ area on epitaxial layers grown at different $\mathrm{C} / \mathrm{Si}$ ratios using methane (closed circles) or ethylene (open circles) as carbon precursor. The C-limited, Si-limited and the cross-over regions are also indicated, similar to Fig. 1.

Further useful information about the surface morphology is provided by the opticalmicroscope images in conjunction with AFM images, as displayed in Fig. 3, 4 and 5 for different $\mathrm{C} / \mathrm{Si}$ ratios. For $\mathrm{C} / \mathrm{Si}<0.7$ (Si-rich condition), regardless of the carbon precursor, the surface morphologies are severely affected by step bunching yielding RMS values of several nm, i.e., several unit cell heights (Fig. 3).This is in line with previous reports on very high step bunching at low $\mathrm{C} / \mathrm{Si}$ ratios [21]. It should be noted that the improvement in surface roughness between $\mathrm{C} / \mathrm{Si}=0.7$ and 0.6 when using ethylene is due to the reduction in growth rate [10]; a similar reduction can be seen also when using methane, but at lower $\mathrm{C} / \mathrm{Si}$ ratios. 


\section{$\mathrm{CH}_{4}$}
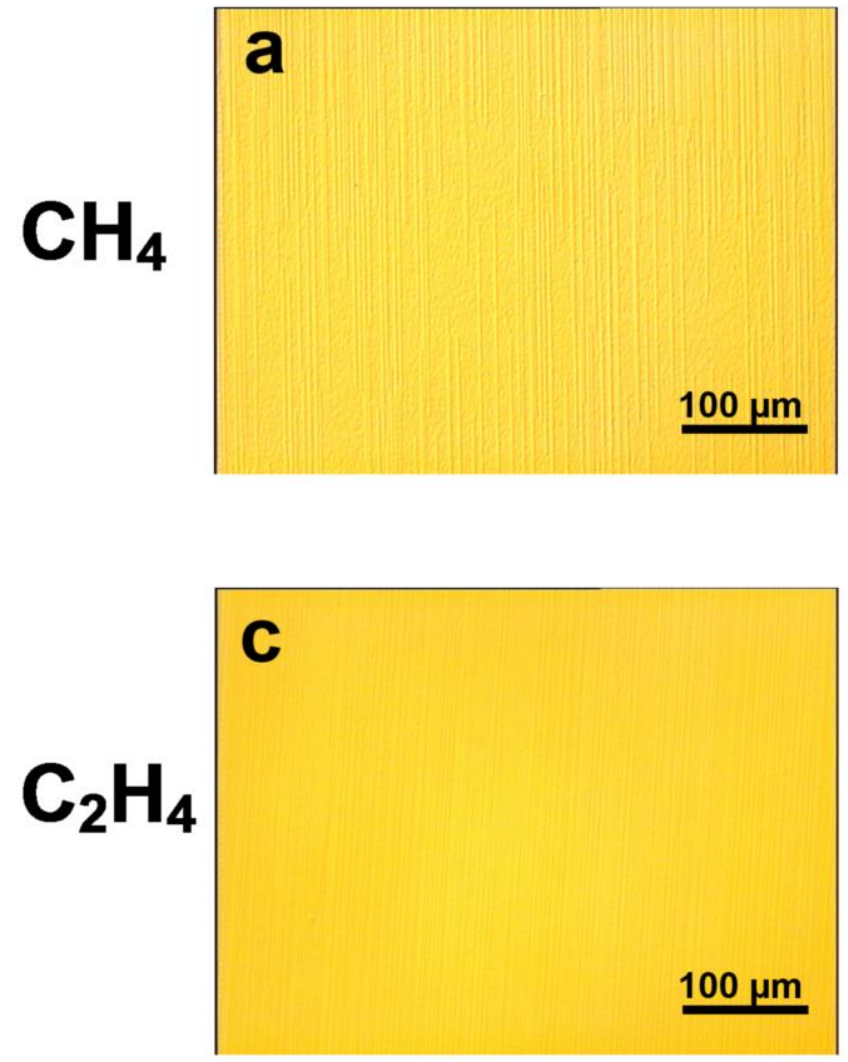
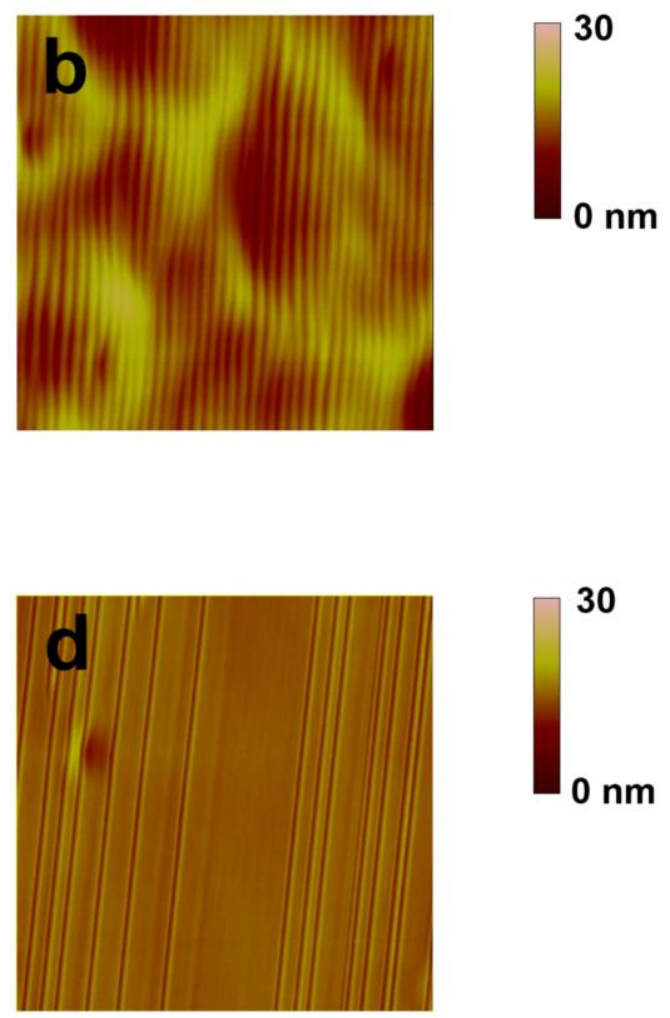

30

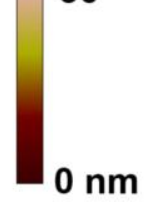

Fig. 3. Optical-microscope and AFM images illustrating the surface morphology of SiC epitaxial layers grown at $\mathrm{C} / \mathrm{Si}=0.6$. When methane is used, a highly step bunched surface with RMS surface roughness value $\sim 3.85 \mathrm{~nm}$ is produced, as seen by optical microscope in a) and AFM in b). Ethylene yields a lower RMS value of $\sim 1.47 \mathrm{~nm}$, but step bunching is still present and seen both by optical microspore in c) and AFM in d).

The growth of epitaxial layers with $\mathrm{C} / \mathrm{Si}>1$ resulted in deteriorated surface morphology. In the layers grown using ethylene, triangular defects were formed similar to those previously reported for growth using propane $\left(\mathrm{C}_{3} \mathrm{H}_{8}\right)$ [22], while growth using methane resulted in a step bunched surface instead (Fig. 4). Thus both the growth rate and the surface morphology indicate that methane and ethylene behave differently in C-rich conditions but have more similar behavior when the growth is done under Si-rich conditions. It can be speculated that the formation of step bunching at $\mathrm{C} / \mathrm{Si}>1$ when using methane, could be 
due to the formation of carbon clusters on the terraces, as such cluster formation has been reported to cause step bunching [21]. This speculation then also implies that adsorbed methane has a low mobility on the terraces.

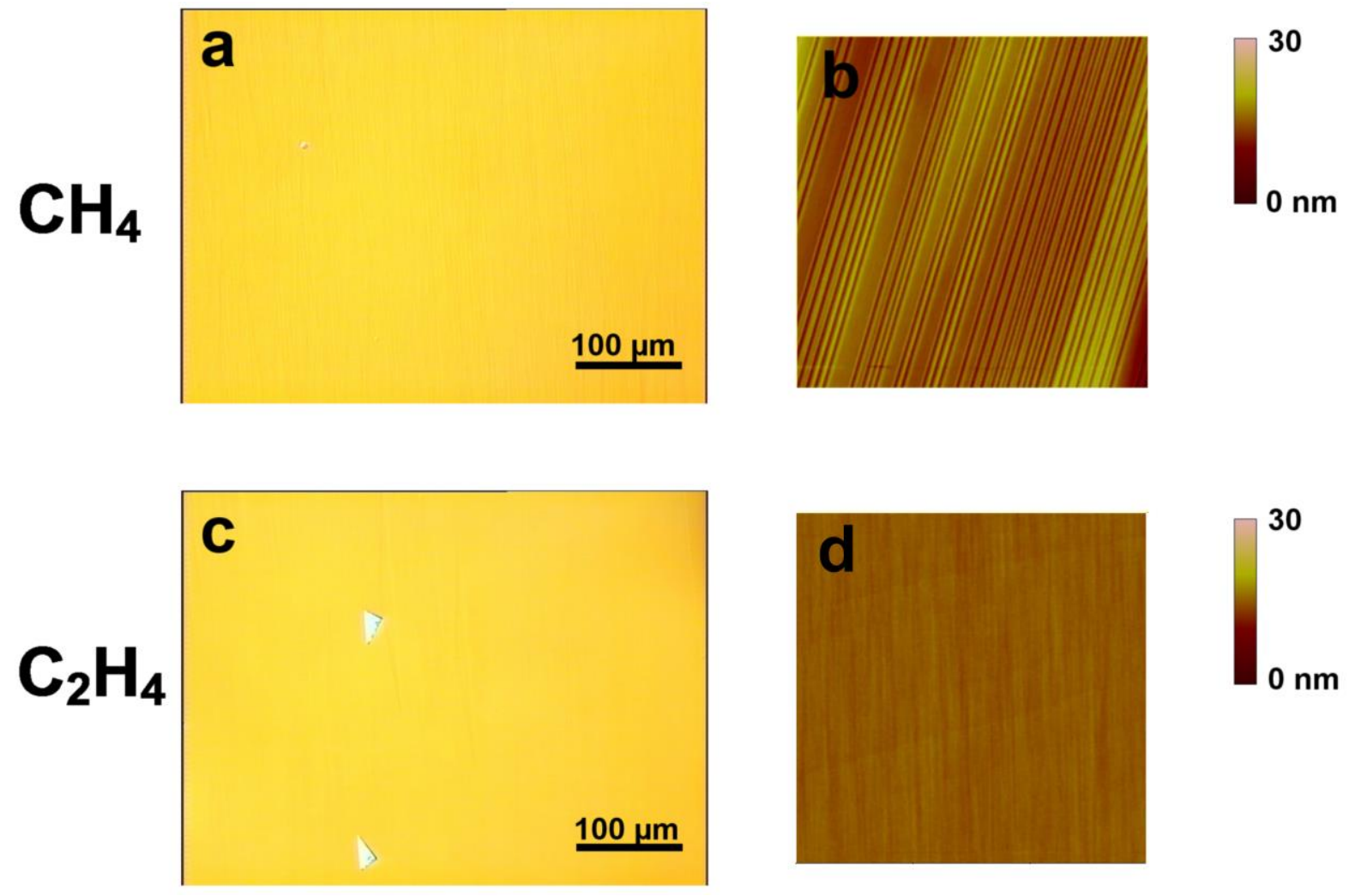

Fig. 4. Surface morphology of $\mathrm{SiC}$ epitaxial layers grown at $\mathrm{C} / \mathrm{Si}=1.2$. Using methane, a step bunched surface, seen by optical microscope in a) and by AFM in b) is produced. Ethylene yields a surface decorated with triangular defects as seen by optical microscope in c), however, the surface is free from step bunching as seen from AFM in d).

For a CVD process using $\mathrm{C}_{2} \mathrm{H}_{4}$, a C/Si ratio of 0.8-1.0 gives excellent morphology with low RMS values of around $0.3 \mathrm{~nm}$ and very low density of surface defects. Using instead $\mathrm{CH}_{4}$ in the CVD process, good morphology is achieved only at C/Si 0.9 with essentially the same (only slightly higher) RMS value compared to the ethylene based process. The important message is that high quality morphology can be achieved also when methane is 
used as carbon precursor, but care should be taken to tune accurately the C/Si ratio to its optimum value, $\mathrm{C} / \mathrm{Si}=0.9$ in our case.

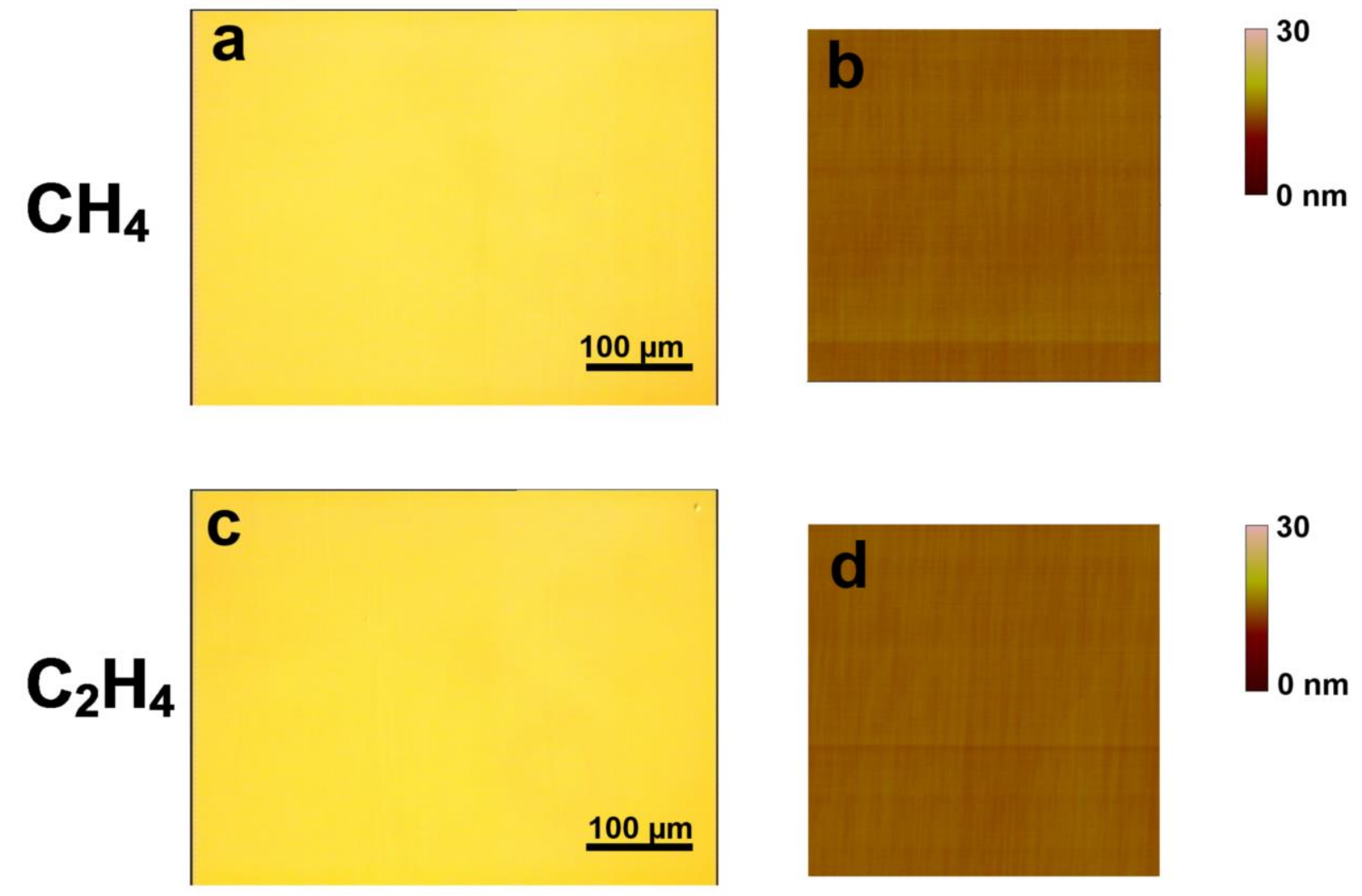

Fig. 5. Surface morphology of $\mathrm{SiC}$ epitaxial layers with very smooth surfaces grown at $\mathrm{C} / \mathrm{Si}=0.9$. The smooth morphology is seen by optical microscope (a) and AFM (b) for growth using methane. The corresponding images for growth using ethylene are, from optical microscope (c) and AFM (d), respectively.

The observed dependence of the morphology on the $\mathrm{C} / \mathrm{Si}$ ratio seems to be a reflection of the more distinct knee point between carbon limited and silicon limited growth for the methane process, Fig. 1. From Fig. 2 it appears as optimal surface morphology is achieved when the growth is done with $\mathrm{C} / \mathrm{Si}$ ratios that renders a growth chemistry that is neither carbon nor silicon limited, i.e. by using a $\mathrm{C} / \mathrm{Si}$ ratio close to the knee point in Fig. 1. Such chemistry is confined to a more narrow $\mathrm{C} / \mathrm{Si}$ range when using methane compared to when using ethylene as carbon precursor, thus giving a more narrow CVD process window, at least for the temperature studied here $\left(1575^{\circ} \mathrm{C}\right)$. 
These observations allude to that our third speculation may be correct i.e. that the methane has a fairly high sticking probability (reactivity) to a Si-H surface, contrary to what is generally assumed. We argue that this value measured by Stinespring et al [16]. may be grossly underestimated based on the fact that there was no hydrogen present during these experiments, the surface is significantly different, and that the experiments were done at substantially lower temperature than those performed in the present study. Further support that methane plays a direct role in the growth is given by the fact that upstream deposits according to Allendorf and Kee's model [15] are insignificant which contradicts our experimental findings where we see heavy deposits upstream of the substrate. A consequence of using a higher sticking of methane in modeling, is a substantial upstream deposition.

We now turn to considering the quality of the epitaxial layers as assessed by LTPL. While not especially sensitive to surface morphology, LTPL provides very useful information about the crystalline quality in the volume of the epitaxial layers. We have examined the LTPL spectra of all samples involved in this study. Typical measurements shown in Fig. 6 illustrate the high crystalline quality of the layers indicated by the sharp strong emission from the free excitons (lines denoted by $I_{x x}$ ) and nitrogen-bound excitons $\left(P_{x x}\right)$, where the subscript $x x$ denotes the energy (in $\mathrm{meV}$ ) of the phonon involved in momentum conservation. Considering only the details of the luminescence spectra it is seen that the spectra of the samples grown with the optimal $\mathrm{C} / \mathrm{Si}=0.9$ are similar to those grown at $\mathrm{C} / \mathrm{Si}$ $=1.2$, bearing witness to the high crystalline quality in the volume of the epitaxial layers in both cases, despite the severe difference in surface morphology. It is also quite obvious that the spectra obtained from samples grown with ethylene are very similar to those from samples grown with methane, for both $\mathrm{C} / \mathrm{Si}$ ratios displayed in Fig. $6 \mathrm{a}$ and 6b, respectively. The main difference between the spectra for $\mathrm{C} / \mathrm{Si}=0.9$ and $\mathrm{C} / \mathrm{Si}=1.2$ (Fig. $6 \mathrm{a}$ and $6 \mathrm{~b}$, 
respectively) is the larger (unintentional) nitrogen-doping level in the former case, as indicated by the diminished relative contribution of the free-exciton emission (lines indexed with I). However, this difference is expected and in agreement with the site-competition mechanism [19]. Indeed, since $\mathrm{C} / \mathrm{Si}=1.2$ corresponds to C-rich conditions, less carbon sites are available to be occupied by nitrogen atoms in this case, leading to lower unintentional doping and higher relative contribution from free excitons.
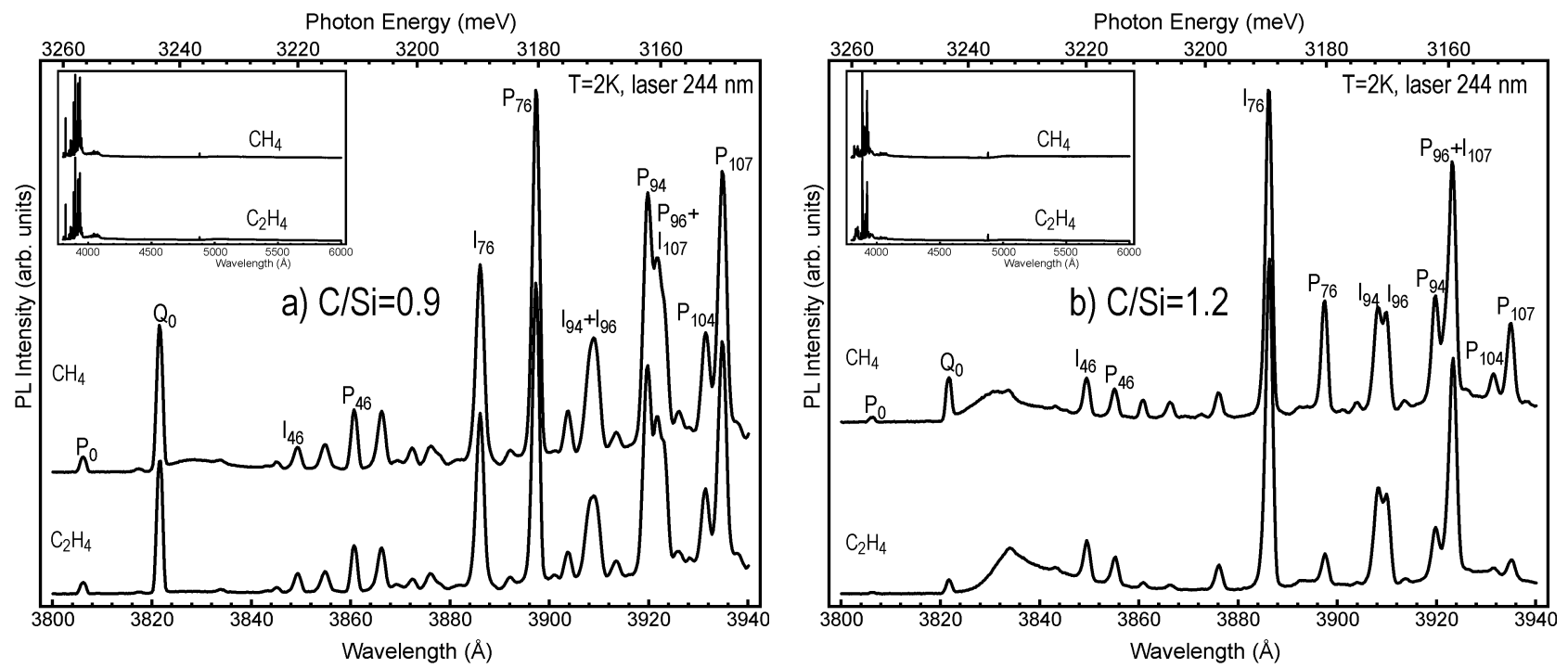

Fig. 6. LTPL spectra showing the near band gap emission of epitaxial layers grown at a) $\mathrm{C} / \mathrm{Si}=0.9$ and b) $\mathrm{C} / \mathrm{Si}=1.2$ using methane (top spectra) and ethylene (bottom spectra). Some of the prominent lines are marked with the letter I (for the free-exciton related lines) and $\mathrm{P}$ (for the $\mathrm{N}$-bound exciton related lines on hexagonal sites) and a subscript showing the energy (in $\mathrm{meV}$ ) of the phonon involved in the transition. Inserts show the full spectra illustrating that no other emission apart from the strong near-band-gap one is observed in the investigated spectral region (the sharp weak line at $488 \mathrm{~nm}$ in the inserted spectra is the second order of the excitation laser line at $244 \mathrm{~nm}$ ). 


\section{Conclusions}

By carefully optimizing the $\mathrm{C} / \mathrm{Si}$ ratio to a growth chemistry that is neither carbon nor silicon limited, the use of methane as carbon precursor in CVD of high quality epitaxial layers of SiC has been demonstrated. The required growth chemistry is shown to be confined to a narrower $\mathrm{C} / \mathrm{Si}$ ratio for CVD using methane compared to CVD using ethylene. This is suggested to be due to differences in growth chemistry caused by the different gas phase chemistry of methane compared to hydrocarbons with C-C bonds. Based on the observed differences in growth behavior, we suggest that the methane molecule takes an active role in the growth and has a substantial sticking probability which is contrary to what is commonly believed today.

\section{Acknowledgements}

Financial support from the Knut and Alice Wallenberg foundation, the Foundation for Strategic Research (SSF) and the Swedish Research Council (VR) is gratefully acknowledged.

\section{References}

[1] H. Matsunami, T. Kimoto, Mater. Sci. Eng. R. 20 (1997) 125.

[2] A. Fissel, A. Phys.rep. 379 (2003) 149.

[3] C. Hallin, I. G. Ivanov, T. Egilsson, A. Henry, O. Kordina, E. Janzén, J. Cryst. Growth 183 (1998) 163.

[4] H. Pedersen, S. Leone, O.Kordina, A. Henry, S. Nishizawa, Y. Koshka, E. Janzén, Chem. Rev. 112 (2012) 2434.

[5] S. Leone, O. Kordina, A. Henry, S. Nishizawa, Ö. Danielsson, E. Janzén, Cryst. Growth. Des. 12 (2012) 1977.

[6] E. Kalered, H. Pedersen, E. Janzén, L. Ojamäe, submitted. 
[7] M. Fanton, D. Snyder, B. Weiland, R. Cavalero, A. Polyakov, M. Skowronski, H. Chung, J. Cryst. Growth. 287 (2006) 359.

[8] E. Janzén and O. Kordina, in Proceedings of the 18TH INTERNATIONAL WORKSHOP ON THERMAL INVESTIGATIONS OF ICS AND SYSTEMS (THERMINIC), Budapest, Hungary, 25-27 September 2012, edited by M. Rencz, P. E. Raad, A. Poppe, B. Courtois, (IEEE, New York, 2012), pp. 119-124.

[9] A. Henry, J. Hassan, J. P. Bergman, C. Hallin, E. Janzén, Chem. Vap. Deposition 12 (2006) 475.

[10] M. Yazdanfar, I. G. Ivanov, H. Pedersen, O. Kordina, E. Janzén, J. Appl. Phys. 113 (2013) 223502.

[11] D. B. Murphy, R. W. Carroll, J. E. Klonowski, Carbon 35 (1997) 1819.

[12] W. Benzinger, K. J. Hüttinger, Carbon. 34 (1996) 1465.

[13] C. D. Stinespring, J. C. Wormhoudt, J. Cryst. Growth. 87 (1988) 481.

[14] M. D. Allendorf, J. Electrochem. Soc. 140 (1993) 747.

[15] M. D. Allendorf, R. J. Kee, J. Electrochem. Soc. 138 (1991) 841.

[16] C. D. Stinespring, J. C. Wormhoudt, J. Appl. Phys. 65 (1989) 1733.

[17] J. Olander, K. Larsson, J. Phys. Chem. B. 105 (2001) 7619.

[18] J. Olander, K. Larsson, Thin Solid Films 458 (2004) 191.

[19] D. Larkin, J. Phys. Status Solisi B. 202 (1997) 305.

[20] H. Pedersen, F. C. Beyer, J. Hassan, A. Henry, E. Janzén, J. Cryst. Growth. 311 (2009) 1321.

[21] Y. Ishida, T. Takahashi, H. Okumura, K. Arai, S. Yoshida. Mater. Sci. Forum. 600-603 (2009) 473.

[22] S. Leone, H. Pedersen, A. Henry, O. Kordina, E. Janzén, J. Cryst. Growth. 311 (2009) 3265. 